
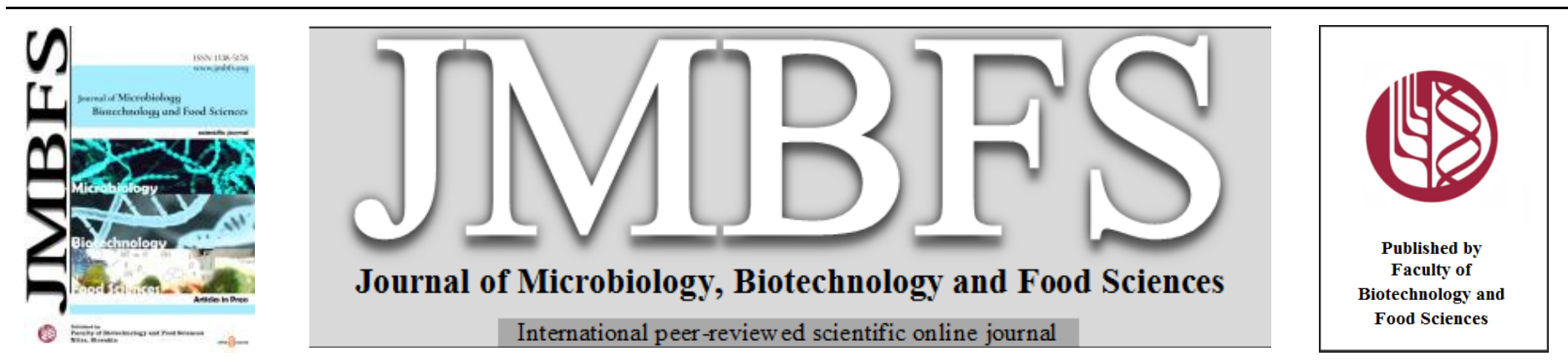

\title{
ETHANOL PRODUCTION FROM SONICATED SWEET SORGHUM BAGASSE BY CO-CULTURE OF PLEUROTUS OSTREATUS AND TRICHODERMA HARZIANUM
}

\author{
James Paul T. Madigal*1, Dane Mikhael S. Calica ${ }^{2}$, Shirley C. Agrupis ${ }^{1}$, and Maria Concepcion B. Birginias ${ }^{4}$
}

Address(es): James Paul T. Madigal,

${ }^{1}$ Mariano Marcos State University, College of Arts and Sciences, Department of Biological Sciences, Brgy. Quiling Sur, 2906, City of Batac, Philippines, Phone number: +639954702204 .

${ }^{2}$ Mariano Marcos State University, Research Directorate, National Bioenergy Research and Innovation Center, Brgy. Quiling Sur, 2906, City of Batac, Philippines, Phone number: +639053585399.

${ }^{3}$ Mariano Marcos State University, College of Arts and Sciences, Department of Biological Sciences, Brgy. Quiling Sur, 2906, City of Batac, Philippines, Phone number: +639276948330 .

${ }^{4}$ Mariano Marcos State University, Research Directorate, Soil and Water Laboratory, Brgy. Quiling Sur, 2906, City of Batac, Philippines, Phone number: +639086223054 .

*Corresponding author: jtmadigal@mmsu.edu.ph

https://doi.org/10.55251/jmbfs.4636

\section{ARTICLE INFO}

Received 31. 3. 2021

Revised 26. 1. 2022

Accepted 28. 1.2022

Published 1. 6. 2022

Regular article OPEN $\bigodot_{\text {ACCESS }}$

\section{ABSTRACT}

The study aimed to develop a novel bioprocessing protocol for lignocellulose conversion into ethanol without the use of any chemical for pre-treatment. The feedstock, mature sweet sorghum bagasse, was milled and sieved to 40 and 80 mesh (physical treatment) to have samples with particle size of $0.425 \mathrm{~mm}$ and $0.180 \mathrm{~mm}$, respectively. After which, samples were inoculated with either single or co-culture of P. ostreatus and T. harzianum (biological) for 28 days followed by sonication (mechanical) with varying time duration. The effectivity of the different treatments under each protocol was evaluated based on delignification and saccharification of the biomass complex via spectrophotometric standard analytical procedure. Cellulose-derived glucose was inoculated with S. cerevisiae under anaerobic conditions to assess its fermentability. Testing of the different treatment combinations was conducted at $5 \mathrm{~g}$ substrate while the best treatment combination was validated at both $5 \mathrm{~g}$ and $100 \mathrm{~g}$ levels. Independent optimization trials of the different treatments showed the significant effect of smaller particle size of $0.180 \mathrm{~mm}$, co-culture of $P$. ostreatus and $T$. harzianum, and sonication time of $20 \mathrm{~min}$ in improving the delignification and saccharification efficiencies of the sweet sorghum biomass. These parameters were combined together as one protocol (physico-bio-mechanical). Saccharification efficiency of this protocol under the $5 \mathrm{~g}$ scale is $\pm 10.67 \%$ against $\pm 9.96 \%$ at $100 \mathrm{~g}$-scale. This is a big leap compared to the $\pm 3.0-5.0 \%$ obtained in our previous experiment. Ethanol yield obtained from the same condition were $2.73 \% \mathrm{w} / \mathrm{w}$ and $1.77 \% \mathrm{w} / \mathrm{w}$ for the $5 \mathrm{~g}$ and $100 \mathrm{~g}$-scale, respectively. It can be confidently stated here, that the present study is the first to ever produce cellulosic ethanol at laboratory-scale condition without chemical pre-treatment.

Keywords: Bioprocessing, delignification, saccharification, cellulose ethanol, lignocellulose

\section{INTRODUCTION}

Lignocellulose is a versatile renewable organic material that can be easily stored and transformed into liquid fuel, electricity, and heat through various processes and is the major structural component of all plants. Lignocellulose consists of three major components: cellulose, hemicellulose and lignin. Lignin is the most recalcitrant component of lignocellulosic material to degrade as it acts as a barrier to enzymes. (Sanchez and Cardona, 2008; Himmel et al., 2007).

In biofuel production, sugars derived from the breakdown of polysaccharides by fungal strains can be converted to ethanol via fermentation. Two of the most ideal fungi used in bioprocessing of lignocellulosic biomass are: 1) Trichoderma sp., capable of producing large amounts of extracelllar cellulases and hemicellulases; and 2) Pleurotus ostreatus, known to have a proficient and selective ability to degrade lignin and can also degrade cellulose and hemicellulose (Kerem $\boldsymbol{e t}$ al., 1992). However, one fungal strain alone cannot produce sufficient amounts of one or more lignocellulolytic enzymes required for efficient bioconversion of lignocellulosic biomass to fermentable sugars. Nonetheless, fungal co-culturing might provide a solution to this problem.

The primary challenge in the conversion of lignocellulosic biomass to ethanol is achieving yields that make it cost-competitive with the current fossil-based fuels The initial conversion of biomass into monomer sugars is a key bottleneck in biofuel production from the non-food biomass of the agricultural sector. Structural carbohydrates especially the cellulose is not readily available to enzymatic hydrolysis, and thus pre-treatment is essential. Conventional processes involve the use of chemicals and high-energy input making the feedstock not commercially and environmentally competitive. These include, steam explosion, liquid hot water
(LHW), ammonia fiber expansion (AFEX), acid cooking, lime, Organosolv extraction, and so on. The main constraints are minimizing sugar degradation and the formation of inhibitors (furanic and phenolic compounds), and limiting the consumption of chemicals, energy and water, and the production of wastes (Yang and Wyman, 2008).

Recent advances show that biotechnological solutions are needed to improve their efficiency to lower overall cost. Some of these advances are the utilization of the Trichoderma reesei cellulolytic enzymes and Saccharomyces cerevisiae yeast strains, alternative and novel schemes are also being investigated, for example, the use of thermophilic enzymes (Viikari et al., 2007), recombinant ethanol-producing strains (Trinh et al., 2008; Yanase $\boldsymbol{e t}$ al., 2007) and consolidated bioprocessing (Shaw et al., 2008).

At Mariano Marcos State University (MMSU), City of Batac, Philippines, a number of pretreatments and processing protocols have been evaluated. Consolidated bioprocessing of market waste using microorganisms from rumen fluid resulted to considerable glucose release. The co-culture of rumen microflora and yeast in another study, achieved relatively high ethanol yield (Agrupis et al., 2010). Previous study also reported the potential of high temperature pretreatment with mild alkaline charge to delignify sweet sorghum bagasse, with subsequent alcoholic fermentation yield of 7.0-9.0\% w/v (Agrupis and Vadlani, 2012). Thus, the present study have developed a combination of physical, biological, and mechanical bioprocessing protocol which is novel, effective, and environmentfriendly protocol for converting lignocellulose biomass to bioethanol. The developed protocol addresses the concern on processing waste residues geared towards the generation of other potential value-added products, therefore, 
establishing a bioprocessing protocol that is eco-friendly, efficient, sustainable, and zero-waste generating.

\section{MATERIAL AND METHODS}

\section{Feedstock preparation and initial compositional analysis}

Sweet sorghum bagasse (Sorghum bicolor L. Moench) was used as the mode feedstock. The bagasse of mature sweet sorghum crops were collected as agricultural waste residues from the MMSU Sweet Sorghum Project. Known mass of the bagasse was subjected to hydro-thermal treatment in a closed vessel at $121^{\circ} \mathrm{C}$ (15 PSI) for 60 minutes to remove the extracellular impurities, hot water extractives including free sugars, and to partially deconstruct the complex matrix of the lignocellulose structure. The bagasse was then filtered while hot to avoid possible re-adsorption of extractible components, washed, dried, and stored until use. Extractive-free samples of sweet sorghum bagasse was subjected to standard laboratory analytical procedures provided by the National Renewable Energy Laboratory (NREL) to determine cellulose, hemicellulose, and lignin. Moreover, using the same protocol, acid insoluble lignin (AIL) and acid soluble lignin (ASL) were determined from the same sample (NREL, 2008).

\section{Physical treatment}

Known mass of extractive-free bagasse was grounded using a Wiley mill, then sieved through 40 and 80 mesh to have samples with particles sizes of $0.425 \mathrm{~mm}$ and $0.180 \mathrm{~mm}$, respectively. After which, they were stored until use.

\section{Fungi cultivation and culture preparation}

Two strains of fungi were used. Fungal strain 1 is a pure culture of Pleurotus ostreatus bought from the Marcos Agro-Industrial School (MAIS), Municipality of Marcos, Province of Ilocos Norte, Philippines, while fungal strain 2 was isolated from naturally decaying biomass of sweet sorghum, which was confirmed to be Trichoderma harzianum. The two fungal strains were re-grown aseptically using standard microbial techniques in Potato Dextrose Broth (PDB) at $30-32^{\circ} \mathrm{C}$ for seven days after incubation (DAI). The spores were then harvested using $9.5 \mathrm{~mL}$ sterile distilled water containing $0.5-\mathrm{mL}$ Tween 80 . The spore suspension was centrifuged at 15,000 rpm for 15 minutes to remove mycelia debris and other impurities. Fungal density was determined by counting the spores through the use of a Haemocytometer.

\section{Sonication}

The efficiency of ultrasound technology in its application for bioprocessing lignocellulosic biomass depends on different operating parameters. In the presen study, the particle size and time duration was investigated. Exactly $2.0 \mathrm{~g}$ of sweet sorghum bagasse was subjected to sonication using an Ultrasonic Processo (UP100H). With particle size as the variable $(0.425 \mathrm{~mm}$, and $0.180 \mathrm{~mm})$, the controlled operating parameters were: a) liquid medium-distilled water; b) loading $-1 / 20(\mathrm{~g} / \mathrm{mL})$; c) cycle-1; d) power and amplitude- $100 \%$; e) working frequency-30 kHz; f) time duration-20 min; and g) temperature-uncontrolled. Varying the time duration at $0,5,10,15$ and 20 minutes, the particle size of 0.180 $\mathrm{mm}$ was used and all other controlled parameters for sonication were similar.

\section{Saccharification using co-culture of $P$. ostreatus and $T$. harzianum}

Accurately $5.0 \mathrm{~g}$ of $0.180 \mathrm{~mm}$ pretreated bagasse was placed in a $250-\mathrm{mL}$ Erlenmeyer flask with $26.0 \mathrm{~mL}$, enough to moisten the biomass, of fermentation medium (Madamwar and Patel, 1992). For the $100 \mathrm{~g}$ sample, 2.0-L Erlenmeyer flask was used containing $520.0 \mathrm{~mL}$ fermentation medium. The set-up was autoclaved at $121^{\circ} \mathrm{C}$ for $30 \mathrm{~min}$ prior to inoculation. Each of the flasks containing the sample and fermentation medium was inoculated with $2.0 \mathrm{~mL}$ of conidiospores from $P$. ostreatus and $T$. harzianum. Separate flasks were inoculated with individual spores of the two fungi. The flask for the co-culture treatment was inoculated with both strains' spores at 1:1 ratio. A control flask containing only the pretreated bagasse and the fermentation medium was also prepared. Incubation was carried out at room temperature. After 28 days, Afterwards, the fungal-treated samples were subjected to sonication and were harvested. Each flask were added with $100.0 \mathrm{~mL}$ water to make a consistency of $5 \%(\mathrm{w} / \mathrm{w})$ and agitated for 5 minutes using a pulse shaker. The suspension was filtered to separately collect the hydrolysate and residue. Using the protocol developed by NREL, collected hydrolysate was subjected to glucose analysis whereas the residue was dried and evaluated for residual acid insoluble lignin (AIL) and acid soluble lignin (ASL) content.

\section{Fermentation of cellulose-derived glucose}

Following the procedure by Agrupis et al. (2012), the treated samples from the previous steps (laboratory scale and smale scale) were inoculated with
Saccharomyces cerevisiae. Fermentation was carried out for seven days. Distillation was done to collect the ethanol produced during fermentation. Ethanol yield was determined and Ethanol conversion efficiency (ECE) was computed as follows:

(1) $\mathrm{ECE}(\%)=\frac{\text { Actual ethanol yield }(\mathrm{g})}{\text { Theoretical ethanol }(\mathrm{g}) \text { based on actual glucose released }(\mathrm{g})} \times 100$

\section{Lignin and structural carbohydrates analyses}

Residual cellulose, hemicellulose, lignin content and glucose released following the protocol developed by (Selig el al., 2008) were determined after the conduct of the experiments that involve sonication. Decrease of cellulose $(\mathrm{C})$, decrease of hemicellulose $(\mathrm{H})$, delignification efficiency $(\mathrm{DE})$, saccharification efficiency (SE), were computed as follows:

(2) Decrease of C $(\%)=\frac{\mathrm{C}(\mathrm{g}) \text { of original sample }-\mathrm{C}(\mathrm{g}) \text { after treatment }}{\underline{\mathrm{C}(\mathrm{g}) \text { of original sample }+\mathrm{C}(\mathrm{g}) \text { after treatment }}} \times 100$

(3) Decrease of $\mathrm{H}(\%)=\frac{\mathrm{H}(\mathrm{g}) \text { of original sample }-\mathrm{H}(\mathrm{g}) \text { after treatment }}{\underline{\mathrm{H}(\mathrm{g}) \text { of original sample }+\mathrm{H}(\mathrm{g}) \text { after treatment }}} \times 100$

(4) $\mathrm{DE}(\%)=\frac{\text { Lignin }(\mathrm{g}) \text { of original sample }- \text { Lignin }(\mathrm{g}) \text { after treatment }}{\underline{\text { Lignin }(\mathrm{g}) \text { of original sample }+ \text { Lignin }(\mathrm{g}) \text { after treatment }}} \times 100$

(5) $\mathrm{SE}(\%)=\frac{\text { Actual glucose released }(\mathrm{g})}{\mathrm{Theoretical}(\mathrm{cucose}(\mathrm{g}) \text { based }}$ 100

\section{Statistical Analysis}

All treatments were done in triplicates. Using IBM SPSS, all the data were analyzed using ANOVA and comparison of means was carried out using LSD and Tukey HSD.

\section{RESULTS AND DISCUSSION}

\section{Composition of sweet sorghum bagasse}

Table 1 shows the biomass composition of extractive-free sweet sorghum bagasse Analysis reveals that it contains $52.02 \pm 0.75 \%$ cellulose, $29.19 \pm 0.34 \%$ hemicellulose, $17.10 \pm 3.55 \%$ acid soluble lignin, and $1.17 \pm 0.03 \%$ acid insoluble lignin. The present study had similar results with the research conducted by Agrupis and Vadlani (2012).

Table 1 Compositional analysis (\%) of extractive-free sweet sorghum bagasse

\begin{tabular}{lc} 
Biomass component & $\%$ \\
\hline Cellulose & $52.02 \pm 0.75$ \\
Hemicellulose & $29.19 \pm 0.34$ \\
Acid Soluble Lignin & $17.10 \pm 3.55$ \\
Acid Insoluble Lignin & $1.17 \pm 0.03$
\end{tabular}

The values represent mean values of triplicate experiments \pm SD

\section{Biodegradation activity of fungi on sweet sorghum bagasse}

Lignocellulosic biomass for ethanol goes through four steps of processing: 1) pretreatment, 2) hydrolysis, 3) fermentation, and 4) distillation, whereas the most important challenge is accredited to pretreatment. The goal of pretreatment is to remove lignin, reduce the crystallinity of cellulose, and increase the porosity of the material. This step is critical because hydrolysis of non-pretreated materials is slow, resulting to low product yield (Mosier et al., 2005). In the present study, the combination of physical (milling) and biological (fungi) pretreatment was investigated.

\section{Delignification}

The cellulose in the plant cell wall is not readily available to enzymatic hydrolysis mainly because of the presence of lignin. Thus, removal of lignin is a prerequisite to allow the efficient recovery of cellulose. The amount of residual lignin reveals the extent of delignification. This denotes that the lesser residual lignin, the greater delignification activity. Table 2 present the delignification effect of fungi on sweet sorghum bagasse subjected to physical pretreatment. Analysis of variance reveals that there is a significant interaction between particle size and fungi. White rot fungi such as Pleurotus ostreatus produce enzymes which are involve in lignin degradation such as laccases that are copper containing enzymes which are involved in lignin degradation. Laccases acts along with lignin peroxidase and manganese peroxidase leading to complete degradation of lignin (Kumar et al., 2015; Kumar and Wyman, 2009). In the present study, noticeably, Pleurotus ostreatus showed the highest percent delignification efficiency of $35.06 \%$ 
compared to Trichoderma harzianum and co-culture treatments due to its ability to produced specific enzymes in initiating lignin degradation.

Table 2 Delignification of sweet sorghum bagasse subjected to physical and fungal treatment

\begin{tabular}{|c|c|c|c|}
\hline \multirow[b]{2}{*}{ Treatment } & \multicolumn{2}{|c|}{ Residual, \%w/w } & \multirow{2}{*}{$\begin{array}{c}\text { Delignification } \\
\text { efficiency, \% }\end{array}$} \\
\hline & $\begin{array}{c}\text { Acid insoluble } \\
\text { lignin }\end{array}$ & $\begin{array}{c}\text { Acid soluble } \\
\text { lignin }\end{array}$ & \\
\hline Particle Size (PS) & $* *$ & $* *$ & $* *$ \\
\hline $0.425 \mathrm{~mm}$ & $15.30^{\mathrm{a}}$ & $0.85^{\mathrm{a}}$ & $13.81^{\mathrm{b}}$ \\
\hline $0.180 \mathrm{~mm}$ & $14.09^{\mathrm{b}}$ & $0.81^{\mathrm{b}}$ & $20.55^{\mathrm{a}}$ \\
\hline Fungi $(\mathrm{F})$ & $* *$ & $* *$ & $* *$ \\
\hline P. ostreatus $(\mathrm{P})$ & $11.69^{c}$ & $0.51^{\mathrm{d}}$ & $35.06^{\mathrm{a}}$ \\
\hline T. harzianum $(\mathrm{T})$ & $16.08^{\mathrm{a}}$ & $0.96^{\mathrm{b}}$ & $9.33^{\mathrm{c}}$ \\
\hline $\mathrm{P}+\mathrm{T}$ & $14.22^{\mathrm{b}}$ & $0.67^{\mathrm{c}}$ & $20.61^{\mathrm{b}}$ \\
\hline Untreated & $16.79^{\mathrm{a}}$ & $1.18^{\mathrm{a}}$ & $3.71^{\mathrm{d}}$ \\
\hline$P S \times F$ & $* *$ & $* *$ & $* *$ \\
\hline $\mathrm{cv}, \%$ & 2.6 & 1.2 & 10.8 \\
\hline
\end{tabular}

** - significant at $1 \%$ level

Through the employment of milling, the biomass is subjected to mechanical comminution. This treatment reduces the particle size of the material, increasing the surface area, rendering the substrate more amenable to succeeding delignification and hydrolysis. As expected, lignin removal was found higher at the smaller particle size of $0.180 \mathrm{~mm}$, hence, we can say that increased surfaced area play a significant role in fungi activity. As regards to fungal treatment, Tables $2 \mathrm{a}$ and $2 \mathrm{~b}$ shows the relatively low residual lignin components of samples treated with $P$. ostreatus hinting its effective lignin degradation. The delignification by $P$. ostreatus $(41.60 \%, 0.180 \mathrm{~mm})$ is higher compared to $T$. harzianum and their coculture (Table 2c). Kerem et al. (1992) documented that this fungus has a specialized lignin metabolism.

Table 2a Interaction effect of particle size and fungi on the residual AIL (\%w/w) of sweet sorghum bagasse

\begin{tabular}{lcccc}
\hline \multirow{2}{*}{ Fungi } & \multicolumn{2}{c}{ Particle Size } & \multirow{2}{*}{ F-Mean } & Difference \\
\cline { 2 - 3 } & $\mathbf{0 . 4 2 5} \mathbf{~ m m}$ & $\mathbf{0 . 1 8 0 ~} \mathbf{~ m m}$ & & \\
\hline P. ostreatus $(\mathrm{P})$ & $12.91^{\mathrm{c}}$ & $10.47^{\mathrm{d}}$ & $11.69^{\mathrm{c}}$ & $2.44^{* *}$ \\
T. harzianum $(\mathrm{T})$ & $16.42^{\mathrm{a}}$ & $15.74^{\mathrm{b}}$ & $16.08^{\mathrm{a}}$ & $0.68^{*}$ \\
P+T & $15.09^{\mathrm{b}}$ & $13.35^{\mathrm{c}}$ & $14.22^{\mathrm{b}}$ & $1.74^{* *}$ \\
Untreated & $16.79^{\mathrm{a}}$ & $16.79^{\mathrm{a}}$ & $16.79^{\mathrm{a}}$ & $0.00^{\mathrm{ns}}$ \\
\hline PS-Mean & $15.30^{\mathrm{a}}$ & $14.09^{\mathrm{b}}$ & 14.7 & 1.22 \\
\hline
\end{tabular}

** - significant at $1 \% ; *$ - significant at $5 \%$; ns - not significant

Table 2b Interaction effect of particle size and fungi on the residual ASL (\%w/w) of sweet sorghum bagasse

\begin{tabular}{lcccc}
\hline \multirow{2}{*}{ Fungi } & \multicolumn{2}{c}{ Particle Size } & \multirow{2}{*}{ F-Mean } & Difference \\
\cline { 2 - 3 } & $\mathbf{0 . 4 2 5} \mathbf{~} \mathbf{m m}$ & $\mathbf{0 . 1 8 0 ~} \mathbf{~ m m}$ & & \\
\hline P. ostreatus $(\mathrm{P})$ & $0.52^{\mathrm{d}}$ & $0.51^{\mathrm{d}}$ & $0.51^{\mathrm{d}}$ & $0.01^{\mathrm{ns}}$ \\
T. harzianum $(\mathrm{T})$ & $1.01^{\mathrm{b}}$ & $0.90^{\mathrm{b}}$ & $0.96^{\mathrm{b}}$ & $0.11^{* *}$ \\
P+T & $0.67^{\mathrm{c}}$ & $0.67^{\mathrm{c}}$ & $0.67^{\mathrm{c}}$ & $0.00^{\mathrm{ns}}$ \\
Untreated & $1.18^{\mathrm{a}}$ & $1.18^{\mathrm{a}}$ & $1.18^{\mathrm{a}}$ & $0.00^{\mathrm{ns}}$ \\
\hline PS-Mean & $0.85^{\mathrm{a}}$ & $0.81^{\mathrm{b}}$ & 0.84 & 0.05 \\
\hline
\end{tabular}

** - significant at $1 \%$; ns - not significant

Table 2c Interaction effect of particle size and fungi on the delignification efficiency $(\%)$ of sweet sorghum bagasse

\begin{tabular}{lcccc}
\hline \multirow{2}{*}{ Fungi } & \multicolumn{2}{c}{ Particle Size } & \multirow{2}{*}{ F-Mean } & Difference \\
\cline { 2 - 3 } & $\mathbf{0 . 4 2 5} \mathbf{~} \mathbf{~ m}$ & $\mathbf{0 . 1 8 0 ~} \mathbf{~ m m}$ & & \\
\hline P. ostreatus $(\mathrm{P})$ & $28.51^{\mathrm{a}}$ & $41.60^{\mathrm{a}}$ & $35.06^{\mathrm{a}}$ & $-13.09^{* *}$ \\
T. harzianum $(\mathrm{T})$ & $7.22^{\mathrm{c}}$ & $11.44^{\mathrm{c}}$ & $9.33^{\mathrm{c}}$ & $-4.22^{*}$ \\
P+T & $15.81^{\mathrm{b}}$ & $25.42^{\mathrm{b}}$ & $20.61^{\mathrm{b}}$ & $-9.61^{* *}$ \\
Untreated & $3.71^{\mathrm{d}}$ & $3.71^{\mathrm{d}}$ & $3.71^{\mathrm{d}}$ & $0.00^{\text {ns }}$ \\
\hline PS-Mean & $13.81^{\mathrm{b}}$ & $20.55^{\mathrm{a}}$ & 17.18 & -6.73 \\
\hline
\end{tabular}

** - significant at $1 \%$; $*$ significant at $5 \%$; ns - not significant

\section{Saccharification}

After delignification, the liberated cellulose can be hydrolyzed to fermentable sugar monomers. Table 3 shows the saccharification effect of fungi on sweet sorghum bagasse subjected to physical pretreatment. Analysis of variance reveals that there is a significant interaction between particle size and fungi.

Table 3 Saccharification of sweet sorghum bagasse subjected to physical and fungal treatment

\begin{tabular}{ccc}
\hline Treatment & $\begin{array}{c}\text { Glucose released, } \\
\text { \% w/w }\end{array}$ & $\begin{array}{c}\text { Saccharification } \\
\text { efficiency, } \%\end{array}$ \\
\hline Particle Size (PS) & $* *$ & $* *$ \\
\hline $0.425 \mathrm{~mm}$ & $2.24^{\mathrm{b}}$ & $4.31^{\mathrm{b}}$ \\
$0.180 \mathrm{~mm}$ & $2.59^{\mathrm{a}}$ & $5.54^{\mathrm{a}}$ \\
\hline Fungi (F) & $* *$ & $* *$ \\
\hline P. ostreatus $(\mathrm{P})$ & $2.28^{\mathrm{b}}$ & $4.46^{\mathrm{c}}$ \\
T. harzianum $(\mathrm{T})$ & $2.64^{\mathrm{b}}$ & $6.12^{\mathrm{b}}$ \\
P+T & $3.81^{\mathrm{a}}$ & $8.91^{\mathrm{a}}$ \\
Untreated & $0.88^{\mathrm{d}}$ & $0.20^{\mathrm{d}}$ \\
\hline PS x F & $* *$ & $* *$ \\
\hline cv, \% & 8.2 & 6.2
\end{tabular}

For the treatment to be considered efficient, cellulose must be hydrolyzed as much as possible with minimum sugar degradation. The results point out that there is higher glucose released and saccharification brought by the fungi at $0.180 \mathrm{~mm}$ (Table $3 \mathrm{a}$ and $3 \mathrm{~b}$ ). This further justifies the noteworthy advantage of smaller particles in the breakdown of structural carbohydrates by fungal enzymes. In line with this, it was found out that the co-culture of $P$. ostreatus and T. harzianum released the highest amount of glucose $(4.16 \% \mathrm{w} / \mathrm{w})$ with its corresponding high saccharification $(9.65 \%)$ at $0.180 \mathrm{~mm}$. This validates the combined efficiency of fungal co-culture in improving the hydrolysis of lignocellulose. In fact, in nature, multiple co-existing lignocellulolytic microorganisms degrade lignocellulosic wastes. Moreover, co-culturing of two or more fungal strains in mixed culture fermentation is widely used in biological processes for different industries, and only recently has it been used for the processing of lignocellulose. The main drawback of co-culturing, however, is the complexity of growing multiple microorganisms in the same culture and was henceforth the subject of extensive research. In this case, we believe that the two fungi synergistically degraded the material, with $P$. ostreatus initiation lignin degradation with subsequent hydrolysis of cellulose by $T$. harzianum. In a recent study by Bilal $\boldsymbol{e t}$ al. (2013), cellulose hydrolysis by the cellulase extract obtained from T. harzianum was recorded up to $56.2 \%$ and $63.8 \%$ in alkali and enzyme treated substrates, respectively. Likewise, $P$. ostreatus contributes to the depolymerization of the structural sugars for it is also capable of producing cellulases (Khalil et al., 2011). The combination of the lignocellulolytic enzymes produced by the two fungi brought about the improved yield.

Table 3a Interaction effect of particle size and fungi on the glucose released (\%w/w) of sweet sorghum bagasse

\begin{tabular}{lcccc}
\hline \multirow{2}{*}{ Fungi } & \multicolumn{2}{c}{ Particle Size } & \multirow{2}{*}{ F-Mean } & Difference \\
\cline { 2 - 3 } & $\mathbf{0 . 4 2 5} \mathbf{~ m m}$ & $\mathbf{0 . 1 8 0 ~} \mathbf{~ m m}$ & & \\
\hline P. ostreatus $(\mathrm{P})$ & $2.36^{\mathrm{b}}$ & $2.20^{\mathrm{c}}$ & $2.28^{\mathrm{b}}$ & $0.16^{\mathrm{ns}}$ \\
T. harzianum $(\mathrm{T})$ & $2.18^{\mathrm{b}}$ & $3.10^{\mathrm{b}}$ & $2.64^{\mathrm{b}}$ & $-0.92^{* *}$ \\
P+T & $3.52^{\mathrm{a}}$ & $4.16^{\mathrm{a}}$ & $3.81^{\mathrm{a}}$ & $-0.64^{* *}$ \\
Untreated & $0.88^{\mathrm{c}}$ & $0.88^{\mathrm{d}}$ & $0.88^{\mathrm{c}}$ & $0.00^{\mathrm{ns}}$ \\
\hline PS-Mean & $2.24^{\mathrm{b}}$ & $2.59^{\mathrm{a}}$ & 2.41 & -0.35 \\
\hline$* *$ - significant at 1\%; ns - not significant & &
\end{tabular}

Table 3b Interaction effect of particle size and fungi on the saccharification efficiency $(\%)$ of sweet sorghum bagasse

\begin{tabular}{ccccc}
\hline \hline \multirow{2}{*}{ Fungi } & \multicolumn{2}{c}{ Particle Size } & \multirow{2}{*}{ F-Mean } & \multirow{2}{*}{ Difference } \\
\cline { 2 - 3 } & $\mathbf{0 . 4 2 5} \mathbf{~ m m}$ & $\mathbf{0 . 1 8 0} \mathbf{~ m m}$ & & \\
\hline P. ostreatus $(\mathrm{P})$ & $3.81^{\mathrm{c}}$ & $5.11^{\mathrm{c}}$ & $4.46^{\mathrm{c}}$ & $-1.30^{* *}$ \\
T. harzianum $(\mathrm{T})$ & $5.05^{\mathrm{b}}$ & $7.18^{\mathrm{b}}$ & $6.12^{\mathrm{b}}$ & $-2.13^{* *}$ \\
P+T & $8.17^{\mathrm{a}}$ & $9.65^{\mathrm{a}}$ & $8.91^{\mathrm{a}}$ & $-1.48^{* *}$ \\
Untreated & $0.20^{\mathrm{d}}$ & $0.20^{\mathrm{d}}$ & $0.20^{\mathrm{d}}$ & $0.00^{\mathrm{ns}}$ \\
\hline PS-Mean & $2.24^{\mathrm{b}}$ & $4.31^{\mathrm{b}}$ & 4.92 & -1.23 \\
\hline \hline
\end{tabular}

** - significant at $1 \%$; ns - not significant 
10

\section{Particle size}

The dynamics, efficacy, and economics of sonication are affected by the particle size of the suspended solids. It is shown in Figure 1 the delignification effect of ultrasound on sweet sorghum bagasse with different particle sizes. Sonication at $0.180 \mathrm{~mm}$ has the highest delignification efficiency at $19.22 \%$. Delignification by ultrasound transpires via the cleavage of inter-unitary bonds within the lignin and lignin-hemicellulose linkages, and hydroxyl attacks on the lignin structure Because the bagasse was subjected to mechanical comminution, the lignocellulose structure was physically augmented by surface erosion allowing enhanced effect of sonication regarding delignification.

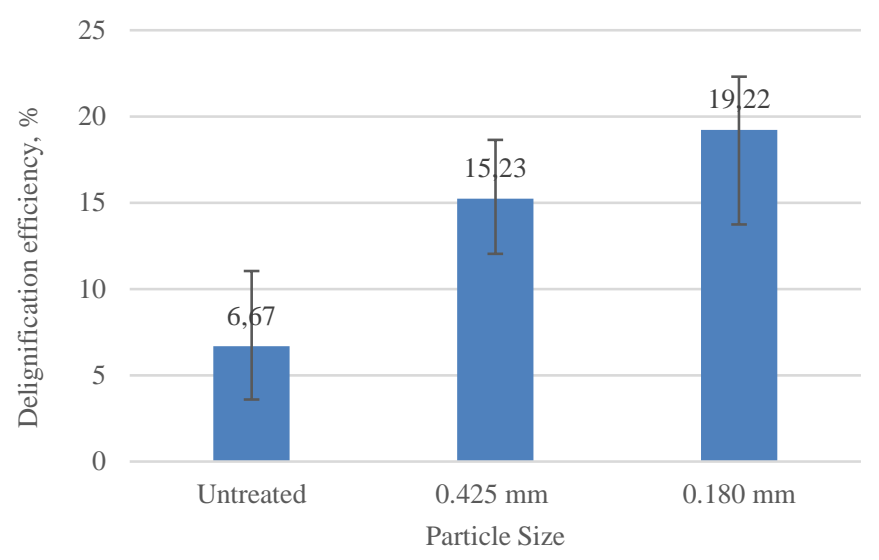

Figure 1 Effect of sonication on the delignification of sweet sorghum bagasse of different particle sizes.

Shown in Table 4 is the degradation of structural carbohydrates of sweet sorghum bagasse with different particle sizes. It is revealed in the analysis of variance that the effect of particle size is significant for the decrease cellulose, hemicellulose, glucose released and saccharification efficiency. Under the influence of sonication, the degradation of structural carbohydrates and saccharification was found highes at $0.180 \mathrm{~mm}$. The mechanoacoustic and sonochemical effects of ultrasound is involved in the degradation of cellulose and hemicellulose via a cumulative effect of hydroxyl attacks, shear forces, and pyrolytic degradation of hydrophobic polymers in the hot region around the collapsing bubbles. At this particle size, better delignification was observed (Table 4) which in turn improved the hydrolysis yields of cellulose. Bussemaker and Zhang (2013) even provided evidence that majority of sonication studies deals with biomass screened to smaller than $1.0 \mathrm{~mm}$. Nevertheless, grinding for smaller particle size is an energy intensive and expensive step. Thus, it is important to consider the efficacy of ultrasound for larger particle sizes.

Table 4 Effect of sonication on the degradation of the structural carbohydrates and saccharification of sweet sorghum bagasse of different particle sizes

\begin{tabular}{|c|c|c|c|c|}
\hline \multirow{2}{*}{$\begin{array}{l}\text { Particle } \\
\text { Size }\end{array}$} & \multicolumn{2}{|c|}{ Decrease, \% } & \multirow{2}{*}{$\begin{array}{c}\text { Glucose } \\
\text { released, } \\
\% \text { w/w }\end{array}$} & \multirow{2}{*}{$\begin{array}{c}\text { Saccharific } \\
\text { ation } \\
\text { efficiency, } \\
\%\end{array}$} \\
\hline & Cellulose & Hemicellulose & & \\
\hline $0.425 \mathrm{~mm}$ & $\begin{array}{l}3.39 \pm \\
0.66^{\mathrm{ab}}\end{array}$ & $18.66 \pm 1.63^{\mathrm{ab}}$ & $\begin{array}{l}2.60 \pm \\
0.09^{\mathrm{ab}}\end{array}$ & $\begin{array}{l}2.98 \pm \\
0.09^{\mathrm{ab}}\end{array}$ \\
\hline $\begin{array}{l}0.180 \mathrm{~mm} \\
\text { Untreated }\end{array}$ & $\begin{array}{l}5.93 \pm 1.27^{\mathrm{a}} \\
2.80 \pm 1.32^{\mathrm{b}}\end{array}$ & $\begin{array}{c}21.11 \pm 3.36^{\mathrm{a}} \\
9.25 \pm 2.70^{\mathrm{b}}\end{array}$ & $\begin{array}{l}4.38 \pm 0.29^{\mathrm{a}} \\
2.04 \pm 0.88^{\mathrm{b}}\end{array}$ & $\begin{array}{l}5.02 \pm 0.33^{\mathrm{a}} \\
2.31 \pm 0.99^{\mathrm{b}}\end{array}$ \\
\hline $\mathrm{cv}, \%$ & 2.8 & 1.6 & 1.8 & 1.8 \\
\hline $\begin{array}{l}\text { Level of } \\
\text { significance }\end{array}$ & $*$ & $* *$ & $* *$ & $* *$ \\
\hline
\end{tabular}

** - significant at $1 \%$ level; $*$ - significant at $5 \%$ level; the values represent mean values of triplicate experiments $\pm \mathrm{SD}$

\section{Time duration}

The duration has notable effect on the results of sonication. Shown in Figure 2 is the delignification effect of sonication with varying time on sweet sorghum bagasse at $0.180 \mathrm{~mm}$. It can be seen that the delignification efficiency was almost linear with prolonged sonication exposure. This can be attributed to improved mass transfer and contact between the liquid medium and the suspended biomass (Sun et al., 2002).

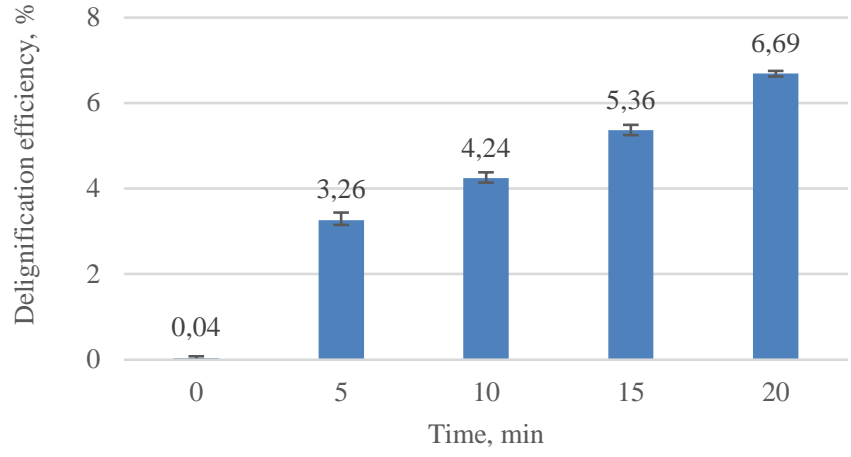

Figure 2 Effect of sonication time on the delignification efficiency of sweet sorghum bagasse at $0.180 \mathrm{~mm}$ particle size

Table 5 shows the degradation of structural carbohydrates and saccharification of sweet sorghum bagasse subjected to sonication with varying time. Analysis of variance reveals that the effect time duration is significant for all the parameters measured. In retrospect, the results on the decrease of cellulose, hemicellulose, glucose released and saccharification efficiency show a similar trend with the removal of lignin. However, the effect of prolonging sonication time is not always accumulative. There are reports that condensation reactions could occur, therefore a less recalcitrant biomass requires shorter ultrasound treatment as compared to a more recalcitrant one. Given that we lack the knowledge on the kinetics of sonication for the different kinds of feedstocks, it is recommended that more work must be conducted to elucidate the mechanisms on how time affects the outcomes of sonication. This will pave way to conception of kinetic models to efficiently implement ultrasound technology.

Table 5 Effect of sonication time on the structural carbohydrates and saccharification of sweet sorghum bagasse at $0.180 \mathrm{~mm}$ particle size

\begin{tabular}{|c|c|c|c|c|}
\hline \multirow{2}{*}{$\begin{array}{l}\text { Time, } \\
\text { min }\end{array}$} & \multicolumn{2}{|c|}{ Decrease, \% } & \multirow{2}{*}{$\begin{array}{c}\text { Glucose } \\
\text { released, } \\
\% \text { w/w } \\
\end{array}$} & \multirow{2}{*}{$\begin{array}{c}\text { Saccharificat } \\
\text { ion } \\
\text { efficiency, \% }\end{array}$} \\
\hline & Cellulose & Hemicellulose & & \\
\hline 0 & $0.00 \pm 0.53^{b}$ & $0.00 \pm 0.36^{\mathrm{c}}$ & $0.77 \pm 0.09^{d}$ & $0.87 \pm 0.10^{\mathrm{d}}$ \\
\hline 5 & $0.33 \pm 0.22^{b}$ & $0.87 \pm 0.17^{\mathrm{c}}$ & $1.92 \pm 0.22^{\mathrm{c}}$ & $2.20 \pm 0.26^{\mathrm{c}}$ \\
\hline 10 & $0.80 \pm 0.67^{b}$ & $1.79 \pm 0.03^{\mathrm{b}}$ & $2.75 \pm 0.08^{b}$ & $3.15 \pm 0.09^{\mathrm{b}}$ \\
\hline 15 & $\begin{array}{l}1.83 \pm \\
0.28^{\mathrm{ab}}\end{array}$ & $2.50 \pm 0.45^{\mathrm{b}}$ & $3.77 \pm 0.37^{\mathrm{a}}$ & $4.30 \pm 0.43^{\mathrm{a}}$ \\
\hline 20 & $2.34 \pm 1.27^{\mathrm{a}}$ & $4.59 \pm 0.90^{\mathrm{a}}$ & $4.34 \pm 0.22^{\mathrm{a}}$ & $5.00 \pm 0.23^{\mathrm{a}}$ \\
\hline $\mathrm{cv}, \%$ & 6.7 & 6.6 & 8.2 & 8.1 \\
\hline $\begin{array}{l}\text { Level of } \\
\text { significan } \\
\text { ce }\end{array}$ & $* *$ & $* *$ & $* *$ & $* *$ \\
\hline
\end{tabular}

Though, the energy of ultrasound is eventually dissipated as heat in the suspension. This means, temperature typically rises in uncontrolled conditions. As shown in Figure 3, temperature rises significantly with increasing duration. The dynamics of sonication-induced cavitation are apparently not affected by changes in temperature over the range of $20-60^{\circ} \mathrm{C}$ as documented by Gogate et al. (2003) Figure 6 reveal that temperature was already at $60^{\circ} \mathrm{C}$ after 5 min of sonication. This elevation simply increases the rates of chemical reactions. Nonetheless, too much temperature rise may be counterproductive. Elevated operating temperature may decelerate the collapse of bubbles during cavitation in compression phase. It is also important to note that solubility of gases in liquids lowers with increased temperature. Although, it was observed in the experiment that there was still considerable degradation occurred in temperatures beyond $60^{\circ} \mathrm{C}$ for sweet sorghum bagasse. Based from the findings, it can be assumed that the effect of temperature on sonication appears to depend on the characteristics of the biomass and other operating parameters. 


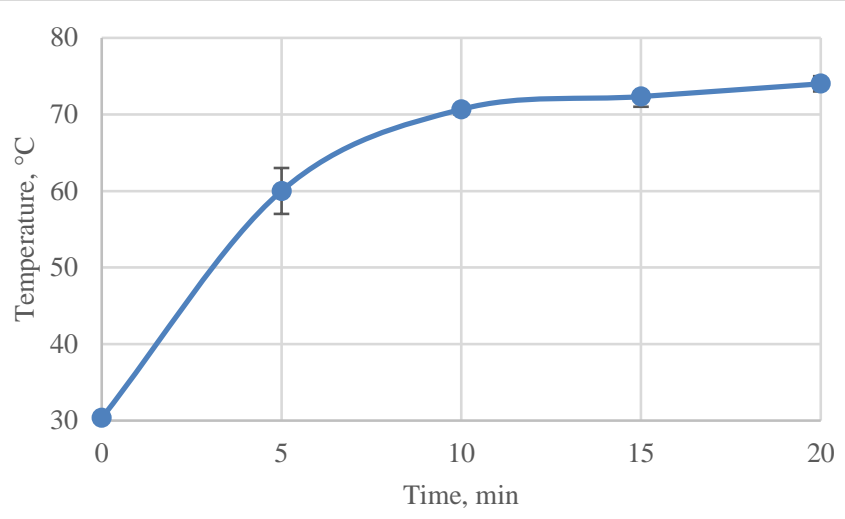

Figure 3 Operating temperature during sonication treatment of sweet sorghum bagasse at $0.180 \mathrm{~mm}$ particle size at different time regimes

\section{Comparison on the effect of sonication on the degradation of fungal-treated sweet sorghum bagasse}

It is known, that in-situ, fungi contribute substantially to the decay of lignocellulosic wastes by producing many different lignocellulolytic enzymes. These enzymes act as catalysts capable of opening the complex structure of lignin by selectively cleaving chemical bonds and depolymerize structural sugars, without the liberation of harmful chemicals to the environment. Because of this, numerous studies have been conducted to advocate the use of fungi in biofuel production for it is both safe and requires low energy input. Adversely, the process is very slow, enzymatically complicated, and requires careful control of growth conditions. It is documented that degradation only increases with prolonged incubation. These insights suggest that there are limitations to the productivity of fungi in their use in the bioprocessing protocol. Interestingly, recent studies reveal that sonication can intensify the effects of several pretreatments. In the study, sonication of fungal treated sweet sorghum bagasse was investigated. The coculture of $P$. ostreatus and T. harzianum, proven earlier to be the best fungal treatment, and the established optimum operating parameters in the use of ultrasound were integrated in the experiment.

Table 6 shows that applying ultrasound instigated further degradation caused by the co-culture of $P$. ostreatus and T. harzianum treated bagasse at $0.180 \mathrm{~mm}$. Analysis of variance reveals that sonication significantly improved all the parameters, except for delignification. The decrease of mass improved by $4.41 \%$, cellulose by $1.68 \%$, and hemicellulose by $2.33 \%$. More to this, glucose released increased by $1.70 \%$, bringing about an increase of saccharification efficiency by $2.96 \%$. These observations can be associated with the disruptive effects of ultrasound to the already destabilized lignocellulosic structure and lysis of fungi to release their enzymes. Additionally, sonication facilitates the removal of hydrolysis products from active sites and consequent binding of enzymes to their substrates (Easson et al., 2011). Studies by Nakao et al. (1990) and Li et al. (2005) assert that yield increases with longer exposure. On the other hand, alongside the cleavage of lignin interunitary bonds and lignin-carbohydrate bonds allowing the subsequent saccharification of structural sugars, evidence for condensation of lignin in the presence of ultrasound was observed in the experiment. The phenomenon of lignin condensation was shown to occur during the same time as lignin extraction. The application of ultrasound can favor the accumulation of reactive species at the bubble interface. This accumulation may enable proton transfer or promote radical scavenging in the hot interfacial region, which would in turn promote recondensation and repolymerization reactions.

Table 6 Effect of sonication on the delignification, degradation of structural carbohydrates, and saccharification on sweet sorghum bagasse subjected to physical and biological treatment

\begin{tabular}{|c|c|c|c|c|c|}
\hline \multirow{2}{*}{ Sonication } & \multirow{2}{*}{ Delignification efficiency, $\%$} & \multicolumn{2}{|c|}{ Decrease, $\%$} & \multirow{2}{*}{ Glucose released, \% w/w } & \multirow{2}{*}{ Saccharification efficiency, $\%$} \\
\hline & & Cellulose & Hemicellulose & & \\
\hline Without & $20.58 \pm 5.34$ & $7.55 \pm 1.21 \mathrm{~b}$ & $14.16 \pm 2.60 \mathrm{~b}$ & $4.01 \pm 0.20 \mathrm{~b}$ & $7.00 \pm 0.34 b$ \\
\hline With & $21.17 \pm 2.38$ & $9.23 \pm 0.58 \mathrm{a}$ & $16.49 \pm 1.36 \mathrm{a}$ & $5.71 \pm 0.13 \mathrm{a}$ & $9.96 \pm 0.24 \mathrm{a}$ \\
\hline $\begin{array}{l}\text { Level of } \\
\text { significance }\end{array}$ & ns & $* *$ & $*$ & $* *$ & $* *$ \\
\hline
\end{tabular}

Fermentability of cellulose-derived glucose from sweet sorghum bagasse subjected to physical, biological, and mechanical treatment

It was mentioned previously that sonication was able to improve the release of glucose and saccharification of sweet sorghum bagasse. Figure 4 shows the effect of ultrasound on the ethanol yield and ethanol conversion efficiency of sweet sorghum bagasse subjected to physical and fungal treatment. It can be inferred from the results that more glucose would yield more ethanol. Conversely, the ethanol conversion efficiency is based on the capability of S. cerevisiae to convert the released glucose to ethanol during fermentation. S. cerevisiae, commonly known as yeast, is the most frequently and traditionally used microorganism for fermenting ethanol at industrial scales (Hahn-Hagerdal et al., 2006). Using yeast in the fermentation process has a few advantages such as its wide public acceptance, high fermentation rate, and high ethanol tolerance. However, anaerobic fermentation of cellulose-derived glucose can be deterred because of the presence of inhibiting compounds (low molecular weight organic acids, furan derivatives, phenolics, and inorganic compounds). These compounds are released and formed during the pretreatment and hydrolysis step. Notably, the lower ethanol yield and ethanol conversion efficiency in samples with sonication suggests the presence of inhibitory compound that would have been release during the sonication treatment. This is an area that needs further study to harness the promise of sonication in biomass processing. Interestingly, yeast is one of the least sensitive microorganisms to the inhibitory effect of lignocellulolytic hydrolysate inhibitors. The results determine that yeast was able to metabolize the cellulose-derived glucose, regardless of concentration, to ethanol at approximately $78.0 \%$ ethanol conversion efficiency.

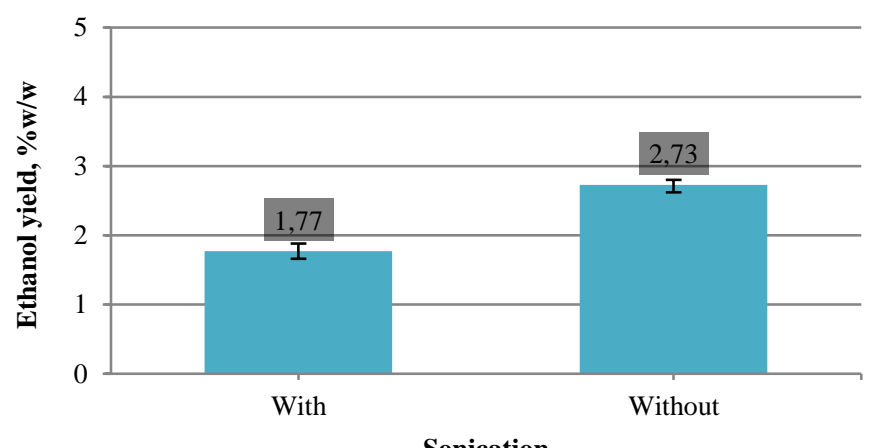

Sonication

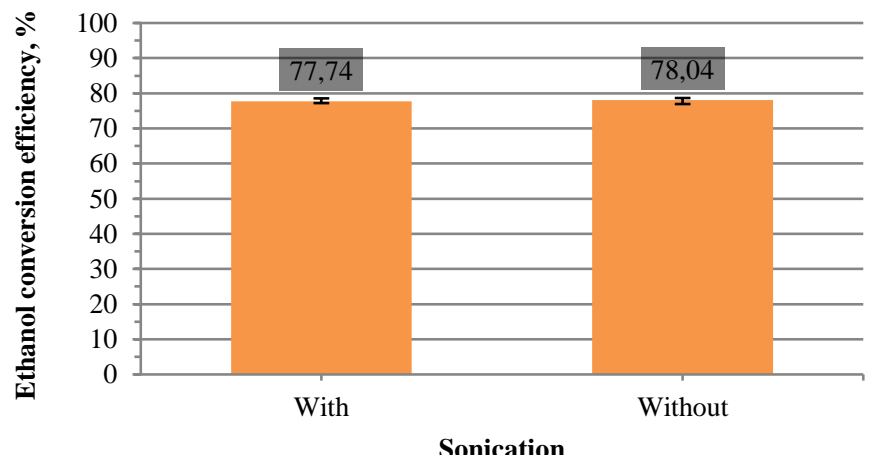

Figure 4 Effect of ultrasound on the ethanol yield and ethanol conversion efficiency of sweet sorghum bagasse subjected to physical and biological treatment. 
Comparison between the $5 \mathrm{~g}$ and $100 \mathrm{~g}$ scale bioprocessing of sweet sorghum bagasse using physico-bio-mechanical treatment

After optimizing the individual stages, the best treatments were combined to develop a novel bioprocessing protocol. It was then tested in $5 \mathrm{~g}$ and $100 \mathrm{~g}$ scales. Problems are commonly associated with large-scale deployment of a technology. In our case, there has been observed changes (Table 7 and Figure 5). Delignification and decrease of cellulose and hemicellulose were found to be lower at the $100 \mathrm{~g}$ scale, although glucose released was higher. On the other hand saccharification efficiency did not exhibit any significant changes. Ethanol yield and ethanol conversion efficiency were evidently lower in the bigger scale. There was a drawback in the productivity of the fungi because the co-culture of $P$. ostreatus and T. harzianum was only given 28 days of incubation for it to proliferate and degrade the larger amount of lignocellulosic biomass. In addition, the main problems encountered in the efficient conversion of the lignocellulosic hydrolysates to ethanol are two-fold. Firstly after pretreatment, the hydrolysate contains not only fermentable sugars, but also a broad range of compounds having inhibitory effects on the microorganisms used for fermentation. The composition of these compounds depends upon the type of lignocellulosic material used and the chemistry and nature of the pretreatment process. Secondly, the hemicellulose hydrolysates contain not only hexoses but also pentoses (Duangwang and Sangwichien, 2015).

Since baker's yeast was used in the present study as fermenting agent, there were two reasons why $100 \mathrm{~g}$ scale yielded lower ethanol than the $5 \mathrm{~g}$ scale. One is that the yeast used does not convert all available sugars present in the lignocellulosic hydrolysate, only those simple sugars like hexoses that the yeast easily fermented or converted into ethanol. Second, the present study did not conduct detoxification step on the lignocellulosic hydrolysate to remove various toxic compounds that will inhibit the yeast performance during fermentation.

More so, subsequent sonication is deterred because of the limitation of the ultrasonic processer $(\mathrm{UP} 100 \mathrm{H})$ used. Given that delignification and saccharification was reduced, we expect lower yields of ethanol. Because of this, the efficacy of this technology at large scale needs to be further evaluated.

Table 7 Comparison between $5 \mathrm{~g}$ scale and $100 \mathrm{~g}$ scale bioprocessing of sweet sorghum bagasse using physical, biological, and mechanical treatment in terms of delignification, degradation of structural carbohydrates, and saccharification

\begin{tabular}{|c|c|c|c|c|c|}
\hline \multirow{2}{*}{ Scale } & \multirow{2}{*}{$\begin{array}{l}\text { Delignification } \\
\text { efficiency, \% }\end{array}$} & \multicolumn{2}{|l|}{ Decrease, \% } & \multirow{2}{*}{$\begin{array}{l}\text { Glucose } \\
\text { released, \% w/w }\end{array}$} & \multirow{2}{*}{$\begin{array}{l}\text { Saccharification } \\
\text { efficiency, } \%\end{array}$} \\
\hline & & Cellulose & Hemicellulose & & \\
\hline $5 \mathrm{~g}$ scale & $27.82 \pm 3.47^{\mathrm{a}}$ & $11.74 \pm 0.74^{\mathrm{a}}$ & $22.94 \pm 1.96^{\mathrm{a}}$ & $4.64 \pm 0.40^{\mathrm{b}}$ & $10.67 \pm 0.95$ \\
\hline $100 \mathrm{~g}$ scale & $21.17 \pm 1.27^{\mathrm{b}}$ & $9.23 \pm 0.61^{\mathrm{b}}$ & $16.49 \pm 1.03^{\mathrm{b}}$ & $5.71 \pm 0.12^{\mathrm{a}}$ & $9.96 \pm 0.22$ \\
\hline $\mathrm{cv}, \%$ & 10.7 & 6.4 & 8.0 & 5.7 & 6.6 \\
\hline $\begin{array}{ll}\text { Level } & \text { of } \\
\text { Significance } & \end{array}$ & $*$ & $*$ & $* *$ & $*$ & ns \\
\hline
\end{tabular}
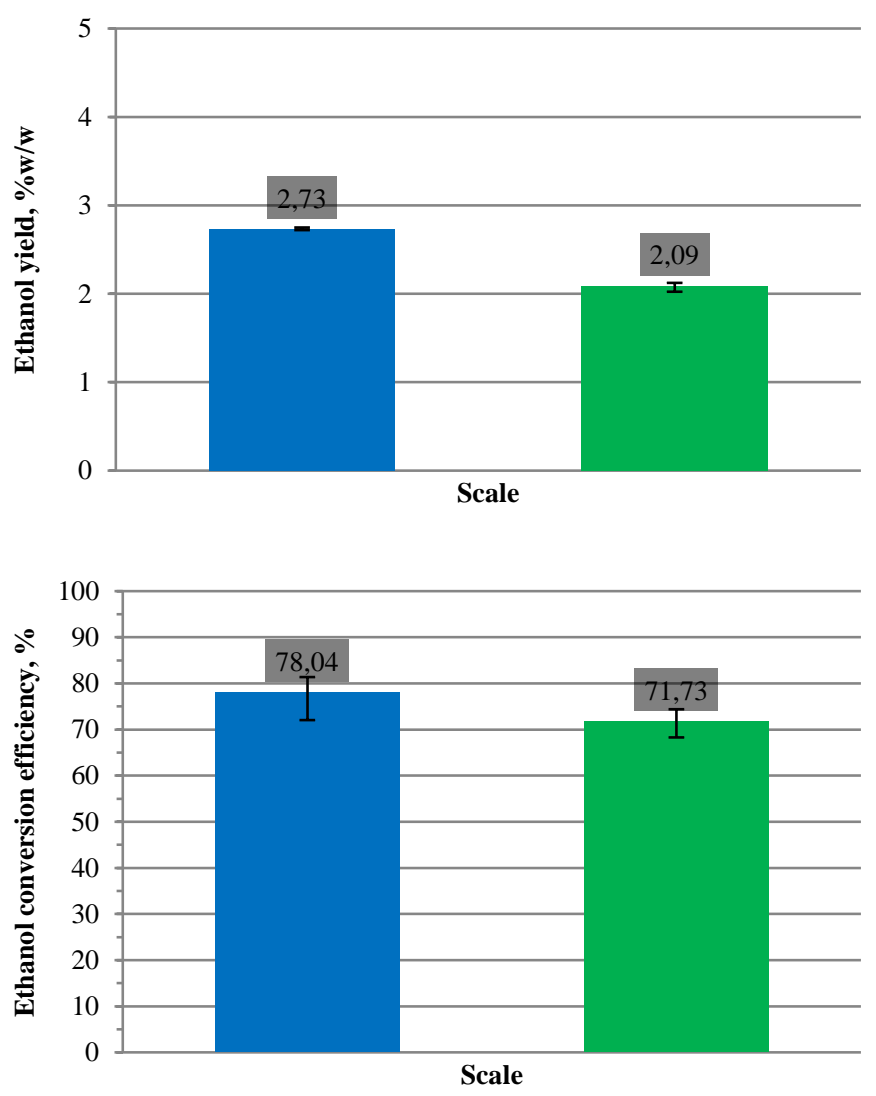

Figure 5 Comparison between $5 \mathrm{~g}$ scale and $100 \mathrm{~g}$ scale bioprocessing of sweet sorghum bagasse using physico-bio-mechanical treatment in terms of ethanol yield and ethanol conversion efficiency

Legend:

$$
5 \mathrm{~g} \text { scale }
$$$$
100 \mathrm{~g} \text { scale }
$$

\section{CONCLUSION}

The data obtained from the delignification and sacchrarification of sweet sorghum bagasse, the model feedstock, served to improve the competitiveness of secondgeneration ethanol production. For the physical treatment, findings have showed that the smaller particle size of $0.180 \mathrm{~mm}$ has the most relevant effect on the degradation by succeeding fungi and ultrasound treatment. In terms of the biological treatment, the co-culture of $P$. ostreatus and $T$. harzianum was documented to have efficiently delignified the material and hydrolyzed the structural carbohydrates better than their monocultures. Moreover, the study validates that sonication as mechanical treatment can improve the release of glucose of the physically and biologically treated biomass bringing about an increased ethanol yield. The developed novel bioprocessing protocol when tested in $5 \mathrm{~g}$ and $100 \mathrm{~g}$ scales showed decreased efficiency in the bigger scale. The protocol is at its early stages of development, but it surely is a potential technique to be optimized, as it does not entail complicated and costly physical processes or the use of environmentally destructive chemicals

Acknowledgements: The authors would like to thank the Philippine Department of Science and Technology (DOST) for funding this research under the MMSU Hydrous Ethanol Project.

\section{REFERENCES}

Agrupis, S.C., Abenes, F.B., \& Ulep, R.A. (2010). Production of Fuel Grade Ethanol from First and Second Generation Feedstocks. Proceedings, ILARRDEC Regional R \& D Review, University of Northern Philippines, Vigan City, Philippines..

Agrupis, S.C, Abenes, F.B, Samsam, C.F., \& Ulep, R.A. (2009). Single Stage Consolidated Process of Producing Ethanol from Biodegradable Mass using Rumen Fluid. Proceedings of the Phil-American Association for Science and Engineering (PAASE); 2009 July 13-14; Ateneo de Manila. Philippines Agrupis, S.C, \& Vadlani, P. (2012). Pretreatment Studies for the Bioprocessing of Sweet Sorghum Non-Grain Biomass. Proceedings, 2012 National Academy of Science and Technology. Manila Hotel, Philippines. July 11-12, 2012.

Agrupis, S.C., Samsam, C.F., \& Ulep, R.A. (2009). Harnessing Lignocellulosic Biomass as Second Generation Feedstock for Bioethanol. Proceedings, PhilAmerican Association for Science and Engineering (PAASE), July 13-14, 2009. Ateneo de Manila. Philippines

Bilal, M., Ashger, M., \& Jamil, F. (2013). Optimization of Bioethanol Production from Old Newspapers Waste Through Alkali and Enzymatic Delignification Using Response Surface Methodology. Proceedings of the 40th Annual Convention on the Applications of Biochemistry and Molecular Biology in Health and Industry: 40 years and beyond; 2013 December 4-5, De La Salle University, Manila, Philippines: of the Philippine Society of Biochemistry and Molecular Biology. p. 72.

Dionisi, D., Anderson, J.A., Aulenta, F., McCue, A., \& Paton, G. (2014). The potential of microbial processes for lignocellulosic biomass conversion to ethanol: a review. Soc Chem Ind 90:366-383. https://doi.org/10.1002/jctb.4544

Duangwang, S. \& Sangwichien, C. (2015). Utilization of Oil Palm Empty Fruit Bunch Hydrolysate for Ethanol Production by Baker's Yeast and Loog-Pang. Energy Procedia 79 ( 2015) $157-162$, Elsevier Ltd. doi: https://doi.org/10.1016/j.egypro.2015.11.455 
Easson, M.W., Condon, B., Dien, B.S., Iten, L., Slopek, R., Yoshioka-Tarver, M. Lambert, A., \& Smith, J. (2011).The Application of Ultrasound in the Enzymatic Hydrolysis of Switchgrass. Applied Biochemistry and Biotechnology 165:1322 1331. https://doi.org/10.1007/s12010-011-9349-1

Gogate, P.R., Wilhelm, A.M. \& Pandit, A.B. (2003). Some Aspects of the Design of Sonochemical Reactors. Ultrasonics Sonochemistry Journal 10:325-330. https://doi.org/10.1016/S1350-4177(03)00103-2

Hahn-Hagerdal, B., Galbe, M., Gorwa-Grauslund, M.F., Liden, G., \& Zacchi, G. (2006). Bioethanol- the Fuel of Tomorrow from the Residue of Today. Trends in Biotechnology. 24:549-556. https://doi.org/10.1016/j.tibtech.2006.10.004

Kerem, Z., Friesem, D., \& Hadar, Y. (1992). Lignocellulose Degradation during Solid-state Fermentation: Pleurotus ostreatus versus Phanerochaete chrysosporium. Applied Environmental Microbiology 58:1121-1127.

Khalil, I., Hoque, M., Basunia, M., Alam, N., \& Khan, A. (2011). Production of Cellulase by Pleurotus ostreatus and Pleurotus sajor-caju in Solid State Fermentation of Lignocellulosic Biomass. Turkish Journal of Agriculture and Forestry 35: 333-341. https://doi.org/10.3906/tar-1002-684

Kumar, G., Bakonyi, P., Periyasamy, S., Kim, S.H., \& Nemestóthy, N. (2015) Lignocellulose biohydrogen: Practical challenges and recent progress. Renew Sustain Energy Rev 44: 728-737.

Kumar, R. \& Wyman, C.E. (2009). Effects of cellulase and xylanase enzymes on the deconstruction of solids from pretreatment of poplar by leading technologies. Biotechnol Prog 25: 302-314.

Li, C.Z., Yoshimoto, M., Ogata, H., Tsukuda, N., Fuku, K., \& Nakao, K. (2005) Effects of Ultrasonic Intensity and Reactor Scale on Kinetics of Enzymatic Saccharification of Various Waste Papers in Continuously Irradiated Stirred Tanks. Ultrasonics $\quad$ Sonochemistry 12:373-384. https://doi.org/10.1016/j.ultsonch.2004.02.004

Madamwar, D. \& Patel, S. (1992). Formation of Cellulases by Co-culturing of Trichoderma reesei and Aspergilus niger on Cellulosic Waste. World Journal of Microbiology and Biotechnology 8:183-186. https://doi.org/10.1007/BF01195843 Mosier, N., Wyman, C., Dale, B., Elander, R., Lee., Y.Y., Holtzapple, M., \& Ladisch, M. (2005). Features of Promising Technologies for Pretreatment of Lignocellulosic Biomass. Bioresource Technology 96:673-686. https://doi.org/10.1016/j.biortech.2004.06.025

Nakao, K., Fukunaga, K., Yasuda, Y., \& Kimura M. (1990). Enzymatic Hydrolysis of Lignocellulosics with Continuous Irradation of Supersonic Wave. Annals of the New York Academy of Sciences 613:802-807.

NREL (National Renewable Energy Laboratory) in Golden, CO. 2008. LAP (Laboratory Analytical Procedure), http://www.nrel.gov/biomass/analytical_procedures.html

Sanchez, O.J. \& Cardona, C.A. (2008). Trends in biotechnological production of fuel ethanol from different feedstocks. Bioresour Technol, 99:5270-5295.

Selig M., Weiss N., \& Ji Y. (2008). Enzymatic saccharification of lignocellulosic biomass. NREL/TP-510-42629. National Renewable Energy Laboratory, Golden, $\mathrm{CO}$

Shaw, A.J., Podkaminer, K.K., Desai, S.G., Bardsley, J.S., Rogers, S.R., Thorne, P.G., Hogsett, D.A., \& Lynd L.R. (2008). Metabolic engineering of a thermophilic bacterium to produce ethanol at high yield. Proc Natl Acad Sci U S A, 105:1376913774.

Sun, R.C., Sun, X.F., \& Ma, X.H. (2002). Effect of Ultrasound on the Structural and Physiochemical Properties of Organosolv Soluble Hemicelluloses from Wheat Straw. Ultrasonics Sonochemtry Journal 9:95-101. https://doi.org/10.1016/s13504177(01)00102-x

Trinh, C.T., Unrean, P., \& Srienc. F. (2008). Minimal Escherichia coli cell for the most efficient production of ethanol from hexoses and pentoses. Appl Environ Microbiol, 74:3634-3643.

Viikari, L., Alapuranen, M., Puranen, T., Vehmaanperä, J., \& Siika-Aho, M. (2007). Thermostable enzymes in lignocellulose hydrolysis

Adv Biochem Eng Biotechnol, 108, pp. 121-145 https://doi.org/10.1007/10_2007_065

Yanase, H., Sato, D., Yamamoto, K., Matsuda, S., Yamamoto, S., \& Okamoto, K. (2007). Genetic engineering of Zymobacter palmae for production of ethanol from xylose. Appl Environ Microbiol, 73:2592-2599. 